\title{
Follistatin-like protein 1 increases transepithelial resistance in kidney epithelial cells through Akt signaling
}

\author{
FEI CHEN ${ }^{1 *}$, QIANG HU ${ }^{2 *}$, HUIHUI HUANG ${ }^{3}$, BINBIN CHEN $^{3}$, YIN XIA $^{3}$ and WENJING LIU ${ }^{4}$ \\ ${ }^{1}$ Department of Nephrology, The First People's Hospital of Yunnan, Kunming University of Sciences and Technology, \\ Kunming, Yunnan 650032; ${ }^{2}$ Department of Emergency Medicine, The Second Affiliated Hospital, Kunming Medical \\ University, Kunming, Yunnan $650101 ;{ }^{3}$ School of Biomedical Sciences, Faculty of Medicine, The Chinese University \\ of Hong Kong, Hong Kong, SAR; ${ }^{4}$ School of Medicine, Yunnan University, Kunming, Yunnan 650091, P.R. China
}

Received May 10, 2016; Accepted May 24, 2017

DOI: $10.3892 / \mathrm{mmr} .2017 .7113$

\begin{abstract}
Tight junctions are intercellular junctional structures that control paracellular permeability across epithelial cell sheets, and serve as a barrier to the intramembranic diffusion of components between apical and basolateral cell membrane domains. Follistatin-like protein 1 (FSTL1) has been reported to promote cellular metabolism and survival. FSTL1 has been revealed to be highly expressed in adult kidney tissues, and high FSTL1 levels have been reported in mouse and human serum samples; however, the roles of FSTL1 in the regulation of kidney function remain to be elucidated. In the present study, FSTL1 was demonstrated to increase the transepithelial electrical resistance in mouse inner medullary collecting duct (mIMCD3) cells. The molecular mechanisms underlying the effects of FSTL1 were also investigated and the results suggested that FSTL1 may exert its actions through the modulation of Akt signaling. In addition, FSTL1 was revealed to produce no effect on the migratory capabilities of mIMCD3 cells. The results of the present study suggested that FSTL1 may facilitate the formation of tight junctions and regulate their function in renal tubular epithelia.
\end{abstract}

\section{Introduction}

The tight junction mediates adhesion between epithelial cells and is required for epithelial cell function (1-4). Tight junctions are a type of specialized intercellular junctional complex which form tight seals between epithelial cells, thus creating a selectively permeable barrier to the diffusion of molecules through the intercellular space $(1,2)$. As a barrier and frontier

Correspondence to: Dr Wenjing Liu, School of Medicine, Yunnan University, 2 Cuihubei Lu Road, Kunming, Yunnan 650091, P.R. China

E-mail: liuwenjing@ynu.edu.cn

${ }^{*}$ Contributed equally

Key words: follistatin-like protein 1, transepithelial electrical resistance, kidney epithelial cells between the basolateral and apical membrane domains of epithelial cells, tight junctions also restrict the diffusion of macromolecules and proteins through intermembrane domains (3). Tight junctions are complex and multi-protein structures, and have been reported to serve critical roles in diverse cellular processes, including the regulation of cellular polarity, differentiation and proliferation (4).

Transepithelial electrical resistance (TER) reflects the paracellular ionic conductance, and has been used to assess the function of the epithelial cell barrier (5). Specific proteins that participate in tight junctions have been reported to be involved in TER modulation (6). Therefore, TER has been widely used to assess the complexity and function of tight junctions, as well as to investigate the physical structures and biological properties of filter-grown epithelial cultures (5).

Follistain-like protein 1 (FSTL1) was originally identified to be a tumor growth factor (TGF)- $\beta$-inducible gene in a mouse osteoblast cell line (7) and is a highly-conserved protein throughout vertebrate evolution (8). FSTL1 consists of an $\mathrm{N}$-terminal domain with homology to follistain (FS domain) and a domain containing two EF-hand calcium-binding sites (EC domain), followed by a C-terminal region homologous to the von Willebrand factor, type $\mathrm{C}$ domain (9). Based on its sequence, FSTL1 can be classified into the secreted protein, acidic and rich in cysteine (SPARC; also known as osteonectin and basement-membrane protein 40, BM-40) family, the members of which have been reported to contain FS and EC domains (9). However, unlike other members of this family, the FS domain of FSTL1 cannot bind activin (10), and its EC domain cannot bind collagen (11). Therefore, this lack of conservation of important functional features suggests that FSTL1 may exhibit unique functional properties.

The function of FSTL1 remains unclear. FSTL1 has been reported to promote cellular metabolism and survival, and to serve important roles in pro- or anti-inflammatory responses in injured tissues (12-23). FSTL1 expression has been demonstrated to increase in the myocardium in response to Akt-induced hypertrophic growth and under conditions of myocardial stress, including ischemia-reperfusion injury and myocardial infarction (12). In addition, it has been revealed to inhibit apoptosis in endothelial cells $(13,14)$ and cardiomyocytes (12), to promote endothelial cell function through 
the modulation of the Akt pathway (14), and to enhance the metastatic potential of prostatic and ovarian cancer cells (15). A recent study by Wei et al (16) demonstrated that FSTL1 delivery into injured myocardial tissue using collagen patches stimulated cardiomyocyte proliferation and the recovery of myocardial function. Furthermore, it has been suggested that FSTL1 may act as an autocrine and endocrine factor, as the levels of circulating FSTL1 have been revealed to be increased in patients with rheumatoid arthritis $(17,18)$, heart failure (19) and acute coronary syndrome (20). FSTL1 expression has been reported to be increased by inflammatory cytokines, including tumor necrosis factor- $\alpha$, interleukin-1 $\beta$, and Toll-like receptor 4 ligands. In addition, FSTL1 has been demonstrated to induce the expression of proinflammatory cytokines and chemokines by activated macrophages $(18,21)$. However, contradictory results have suggested that FSTL1 may suppress the expression of inflammatory cytokines and chemokines $(10,22,23)$. These studies suggest that FSTL1 may function as an inflammatory factor.

FSTL1 has been demonstrated to be robustly expressed in various structures, including the collecting duct in the developing kidney (24). FSTL1 is also expressed in the adult kidney and has been revealed to circulate at high levels in mice and humans. Immunostaining for FSTL1 has indicated its localization in the outer medulla of the adult kidney (25); however, the roles of FSTL1 in the kidney remain to be elucidated. The present study demonstrated that FSTL1 increased TER in mouse inner medullary collecting duct (mIMCD3) cells, whereas its effects appeared to be abolished following the inhibition of Akt signaling. These results suggested that FSTL1 may participate in the molecular mechanisms underlying the regulation of tight junction function in renal tubular epithelia.

\section{Materials and methods}

Cell culture. mIMCD3 cells were purchased from American Type Culture Collection (Manassas, VA, USA; cat no. CRL-2123) (26), and were cultured in high-glucose Dulbecco's modified Eagle's medium (DMEM; Gibco; Thermo Fisher Scientific, Inc., Waltham, MA, USA), supplemented with $10 \%$ fetal bovine serum (FBS; Gibco; Thermo Fisher Scientific, Inc.) and $500 \mu \mathrm{g} / \mathrm{ml}$ penicillin/streptomycin/glutamine. Cells were maintained in a $5 \% \mathrm{CO}_{2}$ humidified atmosphere at $37^{\circ} \mathrm{C}$.

TERevaluation.mIMCD3 cells were seeded $\left(2.5 \times 10^{5}\right.$ cells/well $)$ to form a monolayer in 12-well plates on clear Transwell inserts (0.4 $\mu \mathrm{m}$ pore size; Corning Incorporated, Corning, NY, USA). A total of 3 days following seeding, the culture medium was replaced with fresh DMEM, containing 0, 5, 20 or $100 \mathrm{ng} / \mathrm{ml}$ recombinant human (rh)FSTL1 (GenWay Biotech, Inc., San Diego, CA, USA). TER of mIMCD3 cells was evaluated daily for 5 days using the Millicell Electrical Resistance System (EMD Millipore, Billerica, MA, USA).

To investigate the molecular mechanisms involved in the effects of FSTL1 on TER, mIMCD3 cells were seeded to form a monolayer and the culture medium was replaced with fresh DMEM with or without rhFSTL1 (100 ng/ml). Subsequently, cells were treated with $10 \mu \mathrm{M}$ mitogen-activated protein kinase kinase (MEK) 1/2 inhibitor PD98059 (Cell Signaling Technology, Inc., Danvers, MA, USA), or with $2 \mu \mathrm{M}$ Akt inhibitor VIII, Isozyme-Selective, Akti-1/2 (EMD Millipore) for $30 \mathrm{~min}$. Control cells received no treatment. TER was measured daily for 4 days.

Cell proliferation assay. mIMCD3 cells were seeded $\left(2.5 \times 10^{5}\right.$ cells/well) in triplicate in 12 -well plates. 3 days after seeding, the culture medium was replaced with fresh DMEM, containing 0,20 or $100 \mathrm{ng} / \mathrm{ml} \mathrm{rhFSTL} 1$. Then the cells were counted after 5 days. Proliferation assay was repeated three times, and cell numbers averaged and standard deviations were calculated to permit statistical analysis.

Conditioned medium preparation. An expression vector of HA-tagged FSTL1 was constructed by subcloning the full sequence of the FSTL1 open reading frame tagged with HA into a pCMV vector (Thermo Fisher Scientific, Inc., Waltham, MA, USA). An empty pCMV-HA vector was used for mock transfection (control cells). mIMCD3 cells were seeded $\left(8 \times 10^{5}\right.$ cells/well $)$ in a 6 -well plate in DMEM Medium and transfected with pCMV-HA-FSTL1 or pCMV-HA empty vector, using Lipofectamine ${ }^{\circledR} 2000$ (Thermo Fisher Scientific, Inc.) as the delivery agent, according to the manufacturer's protocol. The conditioned media were collected from cells $48 \mathrm{~h}$ following transfection, and centrifuged at 1,200 rpm for $10 \mathrm{~min}$ at $4^{\circ} \mathrm{C}$ to remove any cells and debris. The pre-cleaned medium was then concentrated from $\sim 120 \mathrm{ml}$ initial volume to $\sim 12 \mathrm{ml}$ final volume using Centriprep YM-3 centrifugal units (EMD Millipore). The amount of proteins in the concentrated conditioned medium was determined using a Bradford protein assay. The protein concentration of prepared media was then adjusted to $2 \mathrm{mg} / \mathrm{ml}$ for further experiments. The prepared stock solution was then mixed with fresh DMEM at a volume ratio of 1:4 (concentrated conditioned medium: DMEM) for further cell cultures. Western blotting was used to detect the expression of FSTL1 in condition medium. Equal amounts of protein samples $(20 \mu \mathrm{g})$ were separated by $10 \%$ SDS-PAGE and transferred onto polyvinylidene difluoride membranes (EMD Millipore). Membranes were blocked at room temperature for $2 \mathrm{~h}$ with $1 \%$ bovine serum albumin (cat. no. P0007; Beyotime Institute of Biotechnology, Haimen, China) in TBST (50 mM Tris- $\mathrm{HCl}, 150 \mathrm{mM} \mathrm{NaCl}$, and $1 \%$ Triton $\mathrm{X}-100, \mathrm{pH} 7.4)$. Membranes were subsequently incubated with goat-anti-FSTL1 antibody (1:1,000 dilution; cat. no. AF1738; R\&D Systems, Inc., Minneapolis, MN, USA) and mouse-anti-HA tag antibody (1:1,000 dilution; cat. no. 05-904; EMD Millipore) at $4^{\circ} \mathrm{C}$ overnight, followed by incubation with horseradish peroxidase-conjugated secondary antibodies donkey anti-goat IgG (cat. no. sc-2056; 1:5,000 dilution; Santa Cruz Biotechnology, Inc., Dallas, TX, USA) and goat anti-mouse IgG (cat. no. sc-2005; 1:5,000 dilution; Santa Cruz Biotechnology, Inc.) at room temperature for $2 \mathrm{~h}$. Protein bands were visualized by enhanced chemiluminescence (ECL), using the Amersham ECL Select Western Blotting Detection Reagent (GE Healthcare Life Sciences, Little Chalfont, UK) followed by exposure to X-ray film (Fujifilm Holdings Corporation, Tokyo, Japan). Membranes were stripped in $0.2 \mathrm{M}$ glycine ( $\mathrm{pH} 2.5$ ) containing $0.5 \%$ Tween-20 for $10 \mathrm{~min}$ and reprobed with anti- $\beta$-actin antibodies (cat. no. sc-7210; 1:3,000 dilution; Santa Cruz Biotechnology, Inc.) at $4^{\circ} \mathrm{C}$ overnight. 
A

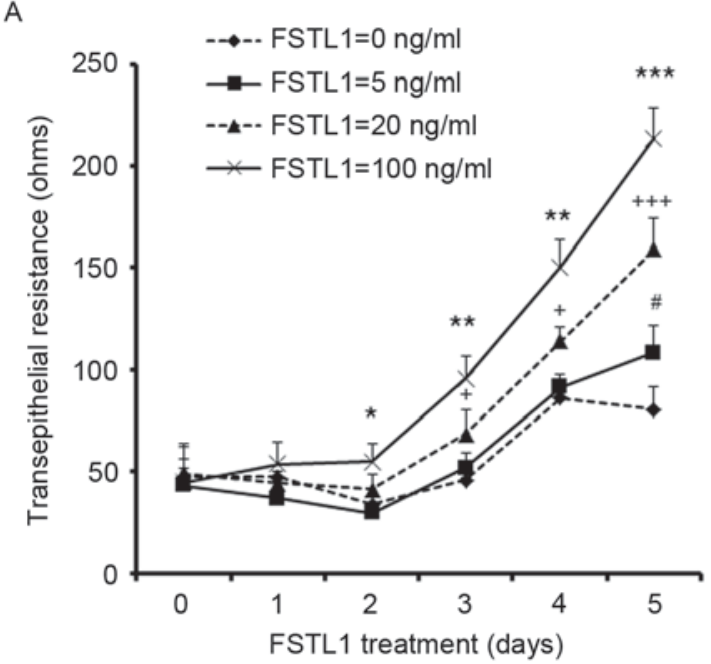

B

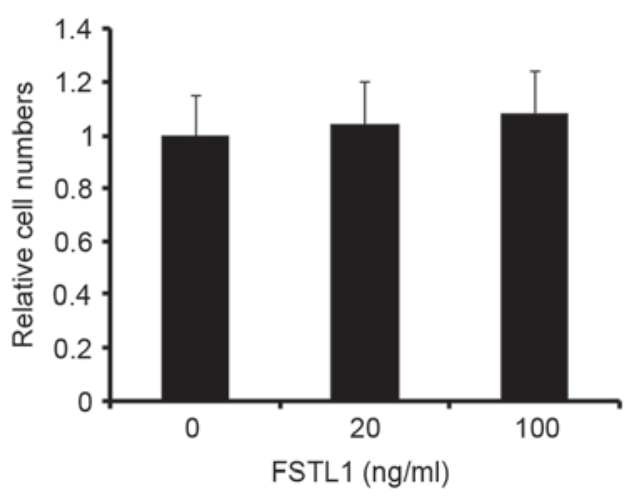

Figure 1. FSTL1 increases TER in mIMCD3 cells. (A) mIMCD3 cells were cultured on Transwell inserts and treated with various concentrations of FSTL1 $(0,5,20$ and $100 \mathrm{ng} / \mathrm{ml})$. TER was measured daily. Treatment with FSTL1 increased TER in a dose-dependent manner. (B) Effects of FSTL1 on mIMCD3 cell proliferation. mIMCD3 cells were cultured in 24-well plates and treated with various concentrations of FSTL1 $(0,20 \mathrm{and} 100 \mathrm{ng} / \mathrm{ml})$. Cell numbers were counted. Treatment with FSTL1 did not affect mIMCD3 cell proliferation. Data are expressed as the mean \pm standard deviation. ${ }^{* *} \mathrm{P}<0.01,{ }^{* * *} \mathrm{P}<0.01$, ${ }^{* * * *} \mathrm{P}<0.001 \mathrm{FSTL} 1100 \mathrm{ng} / \mathrm{ml}$ vs. FSTL1 $0 \mathrm{ng} / \mathrm{ml} ;{ }^{+} \mathrm{P}<0.05,{ }^{++} \mathrm{P}<0.001 \mathrm{FSTL} 120 \mathrm{ng} / \mathrm{ml}$ vs. FSTL1 $0 \mathrm{ng} / \mathrm{ml} ;{ }^{*} \mathrm{P}<0.05 \mathrm{FSTL} 15 \mathrm{ng} / \mathrm{ml}$ vs. FSTL1 0 ng/ml. FSTL-1, follistatin-like protein 1; TER, transepithelial electrical resistance; mIMCD3, mouse inner medullary collecting duct.

Treatment with conditioned medium for cell culture. mIMCD3 cells were seeded $\left(2.5 \times 10^{5}\right.$ cells/well $)$ to form a monolayer in 12 -well plates on clear Transwell inserts $(0.4 \mu \mathrm{m}$ pore size; Corning Incorporated, Corning, NY, USA). A total of 3 days following seeding, the culture medium was replaced with conditioned medium with anti-FSTL1 $(2 \mu \mathrm{g} / \mathrm{ml}$; cat. no. AF1738; R\&D Systems, Inc.) and or normal immunoglobulin $\mathrm{G}$ control ( $2 \mu \mathrm{g} / \mathrm{ml}$; cat. no. AB-108-C; R\&D Systems, Inc.) antibodies overnight. The media of the mIMCD3 cell cultures were changed daily, and TER was measured daily for 3 days.

Western blot analysis. mIMCD3 cells were harvested and lysed in TBST (50 mM Tris- $\mathrm{HCl}, 150 \mathrm{mM} \mathrm{NaCl}$, and $1 \%$ Triton $\mathrm{X}-100, \mathrm{pH}$ 7.4) containing protease and phosphatase inhibitor cocktails (Pierce; Thermo Fisher Scientific, Inc.) for $30 \mathrm{~min}$ on ice. Following centrifugation at 18,341 x $\mathrm{g}$ for $10 \mathrm{~min}$ at $4^{\circ} \mathrm{C}$, the supernatants were collected and protein concentration was determined using a bicinchoninic acid colorimetric assay kit (Pierce; Thermo Fisher Scientific, Inc.). Equal amounts of extracted protein samples $(25 \mu \mathrm{g})$ were separated by $10 \%$ SDS-PAGE and transferred onto polyvinylidene difluoride membranes (EMD Millipore). Membranes were blocked at room temperature for $2 \mathrm{~h}$ with $1 \%$ bovine serum albumin (cat. no. P0007; Beyotime Institute of Biotechnology) in TBST (50 mM Tris- $\mathrm{HCl}$, $150 \mathrm{mM} \mathrm{NaCl}$, and $1 \%$ Triton X-100, pH 7.4). Membranes were then incubated with rabbit anti-phosphorylated (p)-Akt (cat. no. 4058; 1:1,000 dilution; Cell Signaling Technology, Inc.) or anti-p-extracellular signal-regulated kinase (ERK) $1 / 2$ polyclonal primary antibodies (cat. no. 9101; 1:1,000 dilution; Cell Signaling Technology, Inc.) at $4^{\circ} \mathrm{C}$ overnight, followed by incubation with horseradish peroxidase-conjugated secondary antibodies goat anti-rabbit IgG (cat. no. 7074; 1:10,000 dilution; Cell Signaling Technology, Inc.) at room temperature for $2 \mathrm{~h}$. Protein bands were visualized by enhanced chemiluminescence (ECL), using the Amersham
ECL Select Western Blotting Detection Reagent (GE Healthcare Life Sciences, Chalfont, UK) followed by exposure to X-ray film (Fujifilm Holdings Corporation, Tokyo, Japan). Membranes were stripped in $0.2 \mathrm{M}$ glycine ( $\mathrm{pH} 2.5$ ) containing $0.5 \%$ Tween-20 for $10 \mathrm{~min}$ and reprobed with rabbit anti-Akt (cat. no. 9272; 1:1,000 dilution; Cell Signaling Technology, Inc.), anti-ERK1/2 (cat. no. 9102; 1:1,000 dilution; Cell Signaling Technology, Inc.) and anti- $\beta$-actin antibodies (cat. no. sc-7210; 1:3,000 dilution; Santa Cruz Biotechnology, Inc., Dallas, TX, USA) at $4^{\circ} \mathrm{C}$ overnight. The bands were quantified using Multi-Gauge version 3.2 software (Fujifilm Holdings Corporation). Experiments were repeated independently 3 times, and the relative expression of the target protein was normalized to the level of $\beta$-actin in the same sample.

Scratch wound assay. The migratory capabilities of mIMCD3 cells were evaluated using a scratch wound assay. Confluent monolayers of mIMCD3 cells were treated with 0,20 or $100 \mathrm{ng} / \mathrm{ml}$ FSTL1. A scratch wound was inflicted in the monolayer using a micropipette tip (200- $\mu$ l tip) and the culture was rinsed twice with PBS to remove the detached cells. Wound closure was evaluated at 8 and $24 \mathrm{~h}$ following scratching, and photographs were captured by the Zeiss AxionPlan 2 Imaging System light microscope (Zeiss AG, Thornwood, NY, USA). A total of nine areas were selected randomly in each well at x100 magnification, and cells in three wells of each group were quantified in each experiment.

Statistical analysis. The statistical significance of the differences between groups was assessed using one-way analysis of variance followed by Tukey's test. Data are expressed as the mean \pm standard deviation of at least 3 independent experiments. SPSS 12.0 software (SPSS, Inc., Chicago, IL, USA) was used for statistical analysis. $\mathrm{P}<0.05$ was considered to indicate a statistically significant difference. 
A

Control FSTL1 conditioned media

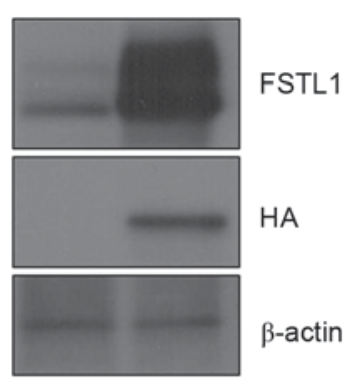

B

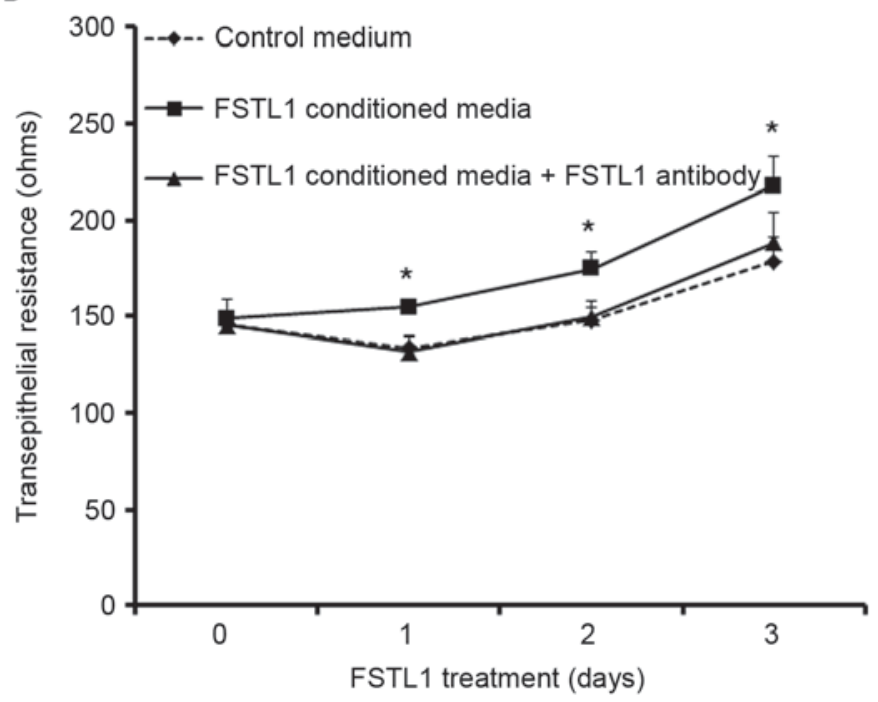

Figure 2. Antibody neutralization of FSTL1 abolishes the effects of FSTL1 conditioned media on mIMCD3 cell TER. (A) FSTL1 expression in conditioned media. mIMCD3 cells were transiently transfected with FSTL1-HA-pCMV. A total of $48 \mathrm{~h}$ post-transfection, FSTL1 conditioned media were harvested and the protein expression levels of FSTL1 and HA were assessed using western blot analysis. (B) Effects of FSTL1 conditioned media on mIMCD3 cell TER. mIMCD3 cells cultured on Transwell inserts at $\sim 90 \%$ confluency were incubated with FSTL1 conditioned media in the presence or absence of anti-FSTL1 antibodies and TER was measured daily. Incubation with FSTL1 conditioned media increased mIMCD3 cell TER, whereas the addition of anti-FSTL1 antibodies abolished this effect. Data are expressed as the mean \pm standard deviation. ${ }^{*} \mathrm{P}<0.05$ vs. FSTL1 conditioned medium + FSTL1 antibody. FSTL-1, follistatin-like protein 1; mIMCD3, mouse inner medullary collecting duct; TER, transepithelial electrical resistance; HA, hemagglutinin.

\section{Results}

FSTL1 increases TER. Tight junctions have been reported to be critical for the maintenance of the normal structure and function of the epithelial cell barrier in the kidneys (3). In the kidneys, TER varies markedly across the various nephron tubules, and is altered in response to physiological and pathological processes (27). FSTL1 has been reported to be highly expressed in the collecting duct during kidney development (28). To investigate whether FSTL1 may regulate the formation of tight junctions, the mIMCD3 well-established renal tubular epithelial cell line was used, which has been demonstrated to form tight junctions in culture (29). In the present study, mIMCD3 cells were plated on Transwell inserts in 12-well plates and the TER was measured. Untreated mIMCD3 cells exhibited a slight increase in TER over the time course of the experiments (Fig. 1A). Following treatment of mIMCD3 cells with various doses of FSTL1, TER was significantly increased compared with untreated control cells. Notably, the effects of FSTL1 on TER were revealed to be dose-dependent (Fig. 1A). The increase in TER did not appear to be due to an increase in cellular proliferation, as indicated by the unaltered mIMCD3 cell numbers following FSTL1 treatment (Fig. 1B).

Secreted FSTL1 increases TER. As FSTL1 is a secreted protein, the conditioned media from mIMCD3 cells were collected, following transfection with HA-tagged FSTL1. The expression of FSTL1 was shown by Fig. 2A. When cultured mIMCD3 cells reached $\sim 90 \%$ confluence, the conditioned media with or without the addition of an anti-FSTL1 antibody were applied. FSTL1 conditioned media were demonstrated to significantly increase TER between days 1 and 3 compared with untreated control cells (Fig. 2B). Addition of the anti-FSTL1 antibody to conditioned media abolished the potentiating effects of FSTL1 on TER (Fig. 2B). These results suggested that FSTL1 may be secreted from renal epithelial cells to induce TER increases.

FSTL1 increases TER through Akt signaling. FSTL1 has been demonstrated to act through phosphatidylinositol-4,5-bisphosphate 3-kinase/Akt and MEK/ERK pathways (17). To investigate the molecular mechanisms underlying the FSTL1-induced increases in TER, the MEK1/2 inhibitor PD98059 was used to evaluate the involvement of ERK signaling pathways. Treatment with FSTL1 was revealed to enhance ERK1/2 phosphorylation in mIMCD3 cells, whereas PD98059 abolished the FSTL1-induced increase in p-ERK1/2 levels (Fig. 3A). Conversely, treatment with PD98059 did not appear to affect the FSTL1-induced increase in TER (Fig. 3B). These results suggested that the MEK1/2/ERK pathway may not be implicated in the mechanisms underlying the potentiating effects of FSTL1 on TER.

In order to evaluate the involvement of Akt signaling in FSTL1-induced increases in TER, the Akt pathway inhibitor VIII was used. Western blot analysis demonstrated that treatment with FSTL1 increased the protein expression levels of p-Akt in mIMCD3 cells, whereas 2 and $10 \mu \mathrm{M}$ of Akt inhibitor VIII were demonstrated to prevent the FSTL1-induced phosphorylation of Akt (Fig. 4A). Notably, Akt inhibitor VIII was revealed to significantly abolish the potentiating effects of FSTL1 on TER, returning it to control levels (Fig. 4B). The present results suggested that FSTL1 may increase TER in renal epithelia through the modulation of the Akt signaling pathway.

FSTL1 does not affect mIMCD3 cell migration. Previous studies have demonstrated that FSTL1 altered the migratory capabilities of several types of cells, including epithelial and 
A

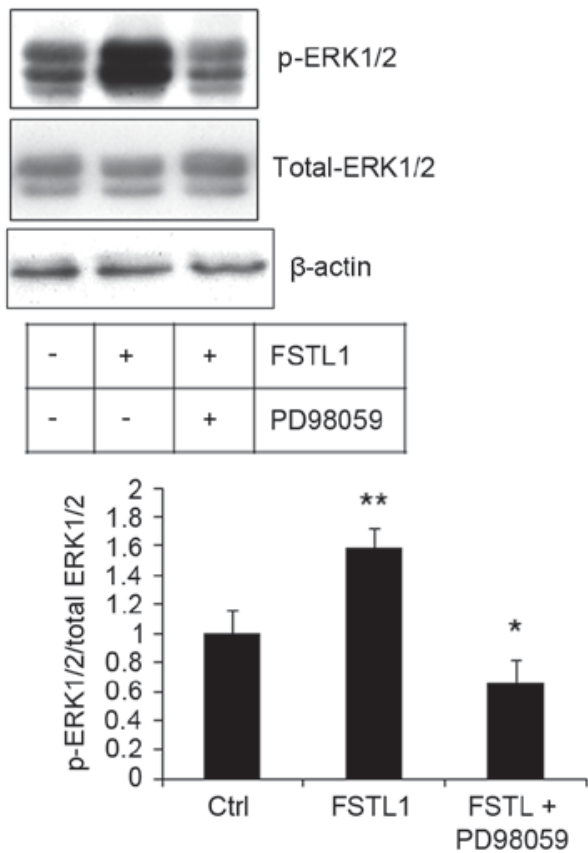

B

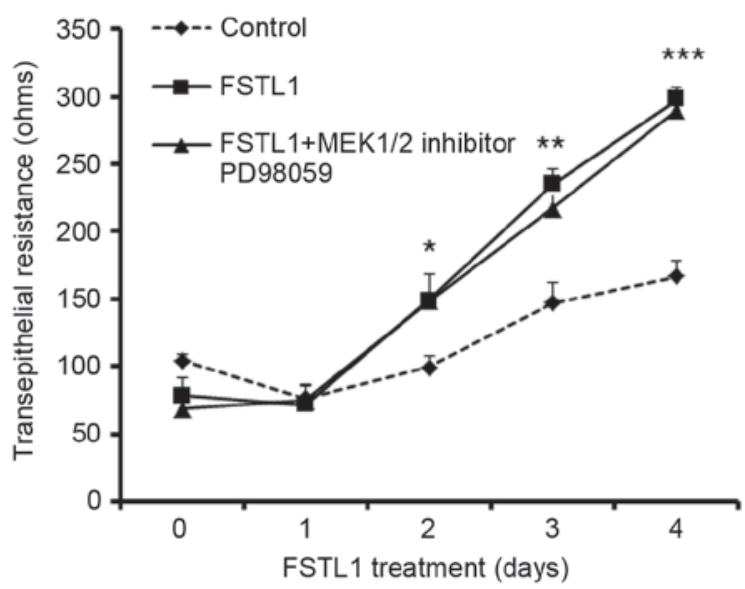

Figure 3. MEK1/2/ERK signaling is not involved in FSTL1-mediated TER increase. (A) Effects of FSTL1 on ERK1/2 phosphorylation in mIMCD3 cells. Cells were treated with or without FSTL1 in the presence or absence of the MEK1/2 inhibitor PD98059. Western blot analysis was used to assess the protein expression levels of total and p-ERK1/2 and results were semi-quantified by densitometry. Data are expressed as the mean \pm standard deviation. ${ }^{*} \mathrm{P}<0.05,{ }^{* *} \mathrm{P}<0.01 \mathrm{vs}$ Ctrl. (B) Effects of the MEK1/2 inhibitor PD98059 on FSTL1-induced TER increase in mIMCD3 cells. Cells cultured on Transwell inserts at 90\% confluency were incubated with FSTL1 in the presence or absence of $10 \mu \mathrm{M}$ PD98059 and TER was measured daily. Ctrl cells received no treatment. The inhibition of MEK1/2 exerted no effect on the FSTL1-induced increase in TER. Data are expressed as the mean \pm standard deviation. ${ }^{*} \mathrm{P}<0.05,{ }^{* * *} \mathrm{P}<0.01,{ }^{* * * *} \mathrm{P}<0.001$ vs. Ctrl MEK, mitogen-activated protein kinase kinase; ERK, extracellular signal-regulated kinase; FSTL-1, follistatin-like protein 1; TER, transepithelial electrical resistance; mIMCD3, mouse inner medullary collecting duct; $\mathrm{p}$, phosphorylated; Ctrl, control.

A
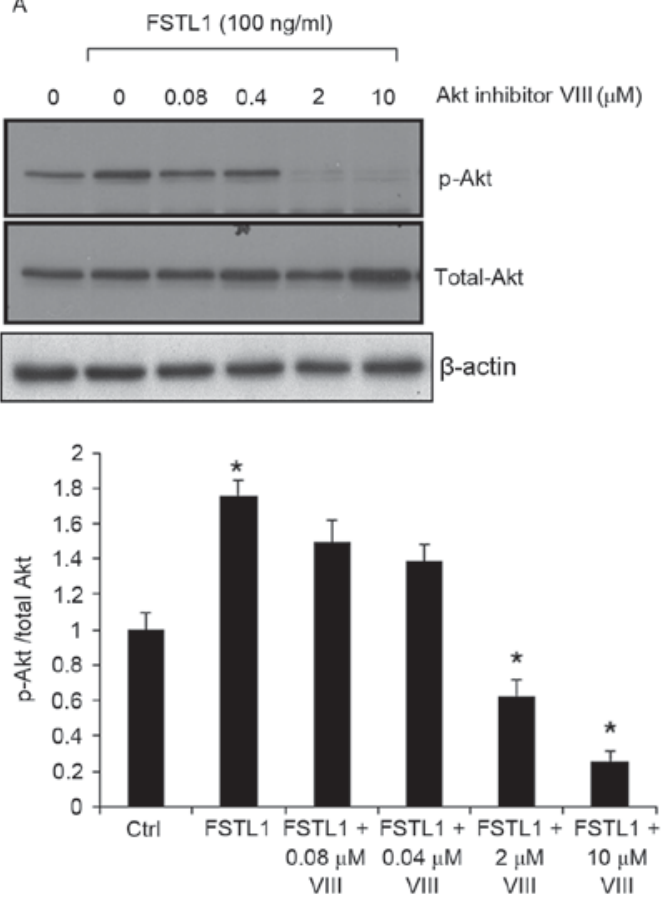

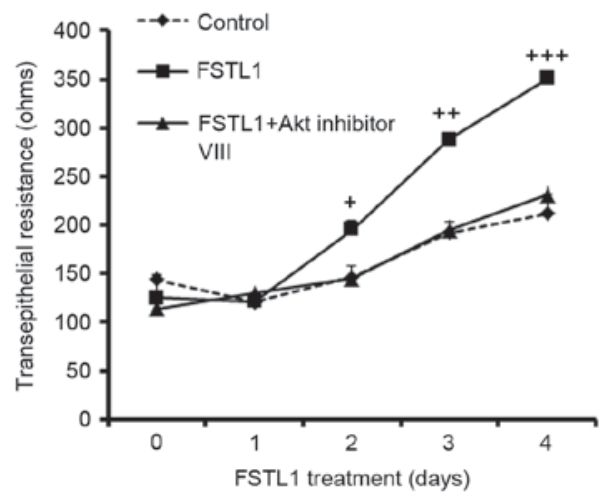

Figure 4. FSTL1 increases TER through Akt signaling. (A) Effects of Akt inhibitor VIII on FSTL1-induced Akt phosphorylation in mIMCD3 cells. Cells were treated with or without FSTL1 $(100 \mathrm{ng} / \mathrm{ml})$ in the presence or absence of various concentrations of Akt inhibitor VIII $(0-10 \mu \mathrm{M})$. Western blot analysis was used to assess the protein expression levels of total and p-Akt, and results were semi-quantified by densitometry. Data are expressed as the mean \pm standard deviation. "P<0.05 vs. Ctrl. (B) Effects of Akt inhibitor VIII on FSTL1-induced TER increase in mIMCD3 cells. Cells cultured on Transwell inserts at $\sim 90 \%$ confluency were incubated with FSTL1 in the presence or absence of $2 \mu \mathrm{M}$ Akt inhibitor VIII and TER was measured daily. Control cells received no treatment. The inhibition of Akt abolished the FSTL1-induced increase in TER. Results are presented as the mean \pm standard deviation of three independent experiments. ${ }^{+} \mathrm{P}<0.05,{ }^{++} \mathrm{P}<0.01,{ }^{++} \mathrm{P}<0.001$ vs. FSTL1 + Akt inhibitor VIII. FSTL-1, follistatin-like protein 1; TER, transepithelial electrical resistance; mIMCD3, mouse inner medullary collecting duct; p, phosphorylated; Ctrl, control. 




Figure 5. FSTL1 is not involved in the regulation of mIMCD3 cell migration. mIMCD3 cells grew to $90 \%$ confluence and cellular migration was evaluated using a scratch wound assay. Scratch wounds were photographed at 0,8 and $24 \mathrm{~h}$ post-scratching. Wound healing was quantified and results demonstrated that treatment with FSTL1 did not exert an effect on the migratory capabilities of mIMCD3 cells. A total of nine areas were selected randomly in each well at x100 magnification, and cells in three wells of each group were quantified in each experiment. Experiments were carried out in triplicate a least three times. Results are presented as the mean \pm standard deviation of three independent experiments. FSTL-1, follistatin-like protein 1; mIMCD3, mouse inner medullary collecting duct.

endothelial cells $(19,30,31)$. To examine the effects of FSTL1 on mIMCD3 cell migration, an in vitro scratch wound assay was performed. Confluent monolayers of mIMCD3 cells were wounded and wound healing was monitored. Treatment with increasing concentrations of FSTL1 did not alter the wound healing speed of mIMCD3 cells (Fig. 5). These results indicated that FSTL1 is not implicated in the regulation of mIMCD3 cell migration.

\section{Discussion}

FSTL1 is expressed in the collecting duct of embryonic kidneys (24), and high circulating FSTL1 levels have been reported in adult mice and humans (25). However, the biological roles of FSTL1 in the kidney are unknown. In the present study, FSTL1 was demonstrated to increase the TER in renal epithelial cells. To the best of our knowledge, this is the first report to suggest a role for FSTL1 in tight junction formation in renal tubular epithelia. Functional tight junctions are essential for the establishment and maintenance of the polarized architecture of epithelial cells (3). Therefore, tight junction modulation may be a critical mechanism during kidney development, as well as during injury and repair. In addition, tight junctions provide a barrier that regulates paracellular and intercellular transport, and in renal tubules, paracellular and intracellular pathways have been implicated in the regulation of epithelial ionic permeability (32). Variations in TER among different segments of the nephron may be involved in the regulation of ionic transport selectivity (33). Therefore, the present results suggested that FSTL1 may serve a role in the development and repair of renal tubules, as well as in tubular function through the regulation of tight junction structure and function.

Akt has been identified to be a key mediator in various intracellular signaling pathways governing cell growth and survival, angiogenesis, as well as in renal tubular transport. Akt has been implicated in insulin signaling via the insulin receptor substrate 2 and the $\mathrm{Na}^{+} / \mathrm{HCO}_{3}{ }^{-}$cotransporter (34), and FSTL1 has been involved in the maintenance of cellular metabolism, through the regulation of Akt signaling $(12,14)$. In the present study, FSTL1 was demonstrated to increase TER in renal epithelial cells, and results suggested that Akt-mediated signaling pathways may be implicated in the molecular mechanisms underlying its actions. FSTL1 is a member the SPARC/BM-40/osteonectin family of proteins which can bind TGF- $\beta$ superfamily proteins and antagonize their binding to their receptors; however, relatively little functional similarity exists between FSTL1 and other family members $(11,35)$. Disco-interacting protein 2 homolog A (DIP2A) has been suggested as a receptor of FSTL1; DIP2A was revealed to be required for the antiapoptotic and promigratory effects of FSTL1 on endothelial cells, and to mediate FSTL1-induced Akt activation (36). Furthermore, DIP2A has been reported to be expressed in mouse kidney tissue (25), thus suggesting that FSTL1 may signal through this receptor to activate Akt intracellular signaling pathways. Further studies are required to elucidate the molecular mechanisms underlying the regulatory effects of FSTL1 on tight junctions in renal tubular epithelia.

FSTL1 was originally identified as a TGF-responsive gene in osteoblasts, and its expression has been demonstrated in various organs in adult organisms (7). FSTL1 expression has been revealed in the kidneys, with the highest expression localized in the outer medulla, and high circulating FSTL1 levels have been reported in adult mice and humans (25). Renal tubules are intimately associated with interstitial blood vessels, thus suggesting that circulating FSTL1 may have access to the majority of renal cells, where it may participate in several processes. Developmental studies have suggested that FSTL1 may be involved in the regulation of organ and tissue formation in embryos (24,37); however, its functions in adults have yet to be fully elucidated. FSTL1 has been demonstrated to promote cellular migration and survival in vitro and in vivo $(14,36,38)$; however, in the present study, FSTL1 did not affect mIMCD3 cell migration. These results suggested that FSTL1 may exert different actions in various types of cells.

In conclusion, the present study demonstrated that FSTL1 increased TER in mIMCD3 cell cultures, through the regulation of Akt-mediated intracellular signaling pathways, but exerted no effects on the migratory capabilities of mIMCD3 cells. These results suggested that FSTL1 may serve important roles in kidney function.

\section{Acknowledgements}

The present study was supported by the startup fund offered by The Chinese University of Hong Kong and a Research Grants Council/General Research Fund grant (grant no. CUHK477311). 
The present study was additionally supported by a grant from the General Scheme of Scientific Research Fund of the Department of Education of Yunnan Province (grant no. 2016ZZX013).

\section{References}

1. Capaldo CT and Nusrat A: Cytokine regulation of tight junctions. Biochim Biophys Acta 1788: 864-871, 2009.

2. Capaldo CT, Farkas AE and Nusrat A: Epithelial adhesive junctions. F1000Prime Rep 6: 1, 2014

3. Shin K, Fogg VC and Margolis B: Tight junctions and cell polarity. Annu Rev Cell Dev Biol 22: 207-235, 2006.

4. Quiros M and Nusrat A: RhoGTPases, actomyosin signaling and regulation of the epithelial apical junctional complex. Semin Cell Dev Biol 36: 194-203, 2014.

5. Blikslager AT, Moeser AJ, Gookin JL, Jones SL and Odle J: Restoration of barrier function in injured intestinal mucosa. Physiol Rev 87: 545-564, 2007.

6. Anderson JM: Molecular structure of tight junctions and their role in epithelial transport. News Physiol Sci 16: 126-130, 2001.

7. Shibanuma M, Mashimo J, Mita A, Kuroki T and Nose K: Cloning from a mouse osteoblastic cell line of a set of transforming-growth-factor-beta 1-regulated genes, one of which seems to encode a follistatin-related polypeptide. Eur J Biochem 217: 13-19, 1993.

8. Zhou J, Liao M, Hatta T, Tanaka M, Xuan X and Fujisaki K: Identification of a follistatin-related protein from the tick Haemaphysalis longicornis and its effect on tick oviposition. Gene 372: 191-198, 2006.

9. Chaly Y, Hostager B, Smith S and Hirsch R: Follistatin-like protein 1 and its role in inflammation and inflammatory diseases. Immunol Res 59: 266-272, 2014.

10. Kawabata D, Tanaka M, Fujii T, Umehara H, Fujita Y, Yoshifuji H Mimori T and Ozaki S: Ameliorative effects of follistatin-related protein/TSC-36/FSTL1 on joint inflammation in a mouse model of arthritis. Arthritis Rheum 50: 660-668, 2004.

11. Hambrock HO, Kaufmann B, Müller S, Hanisch FG, Nose K Paulsson M, Maurer P and Hartmann U: Structural characterization of TSC-36/Flik: Analysis of two charge 'isoforms. J Biol Chem 279: 11727-11735, 2004.

12. Oshima Y, Ouchi N, Sato K, Izumiya Y, Pimentel DR and Walsh K: Follistatin-like 1 is an Akt-regulated cardioprotective factor that is secreted by the heart. Circulation 117: 3099-3108, 2008.

13. Liu S, Shen H, Xu M, Liu O, Zhao L, Liu S, Guo Z and Du J: FRP inhibits ox-LDL-induced endothelial cell apoptosis through an Akt-NF-\{kappa\}B-Bcl-2 pathway and inhibits endothelial cell apoptosis in an apoE-knockout mouse model. Am J Physiol Endocrinol Metab 299: E351-E363, 2010.

14. Ouchi N, Oshima Y, Ohashi K, Higuchi A, Ikegami C, Izumiya $\mathrm{Y}$ and Walsh K: Follistatin-like 1, a secreted muscle protein, promotes endothelial cell function and revascularization in ischemic tissue through a nitric-oxide synthase-dependent mechanism. J Biol Chem 283: 32802-32811, 2008.

15. Chan QK, Ngan HY, Ip PP, Liu VW, Xue WC and Cheung AN: Tumor suppressor effect of follistatin-like 1 in ovarian and endometrial carcinogenesis: A differential expression and functional analysis. Carcinogenesis 30: 114-121, 2009.

16. Wei K, Serpooshan V, Hurtado C, Diez-Cuñado M, Zhao M, Maruyama S, Zhu W, Fajardo G, Noseda M, Nakamura K, et al: Epicardial FSTL1 reconstitution regenerates the adult mammalian heart. Nature 525: 479-485, 2015.

17. Wang Y, Li D, Xu N, Tao W, Zhu R, Sun R, Fan W, Zhang P, Dong T and Yu L: Follistatin-like protein 1: A serum biochemical marker reflecting the severity of joint damage in patients with osteoarthritis. Arthritis Res Ther 13: R193, 2011.

18. Chaly Y, Marinov AD, Oxburgh L, Bushnell DS and Hirsch R: FSTL1 promotes arthritis in mice by enhancing inflammatory cytokine/chemokine expression. Arthritis Rheum 64: 1082-1088, 2012.

19. El-Armouche A, Ouchi N, Tanaka K, Doros G, Wittköpper K, Schulze T, Eschenhagen T, Walsh K and Sam F: Follistatin-like 1 in chronic systolic heart failure: A marker of left ventricular remodeling. Circ Heart Fail 4: 621-627, 2011.
20. Widera C, Giannitsis E, Kempf T, Korf-Klingebiel M, Fiedler B, Sharma S, Katus HA, Asaumi Y, Shimano M, Walsh K and Wollert KC: Identification of follistatin-like 1 by expression cloning as an activator of the growth differentiation factor 15 gene and a prognostic biomarker in acute coronary syndrome. Clin Chem 58: 1233-1241, 2012.

21. Chaly Y, Fu Y, Marinov A, Hostager B, Yan W, Campfield B, Kellum JA, Bushnell D, Wang Y, Vockley J and Hirsch R: Follistatin-like protein 1 enhances NLRP3 inflammasome-mediated IL-1 $\beta$ secretion from monocytes and macrophages. Eur J Immunol 44: 1467-1479, 2014.

22. Le Luduec JB, Condamine T, Louvet C, Thebault P, Heslan JM, Heslan M, Chiffoleau E and Cuturi MC: An immunomodulatory role for follistatin-like 1 in heart allograft transplantation. Am J Transplant 8: 2297-2306, 2008.

23. Tanaka M, Ozaki S, Kawabata D, Kishimura M, Osakada F, Okubo M, Murakami M, Nakao K and Mimori T: Potential preventive effects of follistatin-related protein/TSC-36 on joint destruction and antagonistic modulation of its autoantibodies in rheumatoid arthritis. Int Immunol 15: 71-77, 2003.

24. Adams D, Larman B and Oxburgh L: Developmental expression of mouse Follistatin-like 1 (Fst11): Dynamic regulation during organogenesis of the kidney and lung. Gene Expr Patterns 7: 491-500, 2007.

25. Adams DC, Karolak MJ, Larman BW, Liaw L, Nolin JD and Oxburgh L: Follistatin-like 1 regulates renal IL-1 $\beta$ expression in cisplatin nephrotoxicity. Am J Physiol Renal Physiol 299: F1320-F1327, 2010.

26. Rauchman MI, Nigam SK, Delpire E and Gullans SR: An osmotically tolerant inner medullary collecting duct cell line from an SV40 transgenic mouse. Am J Physiol 265: F416-F424, 1993.

27. Brown D and Stow JL: Protein trafficking and polarity in kidney epithelium: From cell biology to physiology. Physiol Rev 76: 245-297, 1996

28. Xu J, Qi X, Gong J, Yu M, Zhang F, Sha H and Gao X: Fstl1 antagonizes BMP signaling and regulates ureter development. PLoS One 7: e32554, 2012.

29. Xia Y, Babitt JL, Bouley R, Zhang Y, Da Silva N, Chen S, Zhuang Z, Samad TA, Brenner GJ, Anderson JL, et al: Dragon enhances BMP signaling and increases transepithelial resistance in kidney epithelial cells. J Am Soc Nephrol 21: 666-677, 2010.

30. Chen SX, Xu XE, Wang XQ, Cui SJ, Xu LL, Jiang YH, Zhang Y, Yan HB, Zhang Q, Qiao J, et al: Identification of colonic fibroblast secretomes reveals secretory factors regulating colon cancer cell proliferation. J Proteomics 110: 155-171, 2014.

31. Miyabe M, Ohashi K, Shibata R, Uemura Y, Ogura Y, Yuasa D, Kambara T, Kataoka Y, Yamamoto T, Matsuo K, et al: Muscle-derived follistatin-like 1 functions to reduce neointimal formation after vascular injury. Cardiovasc Res 103: 111-120, 2014.

32. Yamauchi K, Rai T, Kobayashi K, Sohara E, Suzuki T, Itoh T, Suda S, Hayama A, Sasaki S and Uchida S: Disease-causing mutant WNK4 increases paracellular chloride permeability and phosphorylates claudins. Proc Natl Acad Sci USA 101: 4690-4694, 2004.

33. Reyes JL, Lamas M, Martin D, del Carmen Namorado M, Islas S, Luna J, Tauc M and González-Mariscal L: The renal segmental distribution of claudins changes with development. Kidney Int 62: 476-487, 2002

34. Satoh N, Nakamura M, Suzuki M, Suzuki A, Seki G and Horita S: Roles of Akt and SGK1 in the regulation of renal tubular transport. Biomed Res Int 2015: 971697, 2015.

35. Balemans W and Van Hul W: Extracellular regulation of BMP signaling in vertebrates: A cocktail of modulators. Dev Biol 250: 231-250, 2002.

36. Ouchi N, Asaumi Y, Ohashi K, Higuchi A, Sono-Romanelli S, Oshima Y and Walsh K: DIP2A functions as a FSTL1 receptor. J Biol Chem 285: 7127-7134, 2010.

37. Sylva M, Moorman AF and van den Hoff MJ: Follistatin-like 1 in vertebrate development. Birth Defects Res C Embryo Today 99: 61-69, 2013

38. Liang X, Hu Q, Li B, McBride D, Bian H, Spagnoli P, Chen D, Tang $\mathrm{J}$ and Zhang JH: Follistatin-like 1 attenuates apoptosis via disco-interacting protein 2 homolog A/Akt pathway after middle cerebral artery occlusion in rats. Stroke 45: 3048-3054, 2014. 